\title{
Nuclear reaction analysis for composition measurement of BN thin films
}

\author{
T. Kobayashi \\ Tsuyama National College of Technology \\ t-koba@tsuyama-ct.ac.jp \\ H. Kanematsu \\ Suzuka National College of Technology \\ kanemats@mse.suzuka-ct.ac.jp
}

\section{EXPERIMENTAL AND RESULTt}

The composition of the $\mathrm{BN}$ film was determined using Rutherford backscattering spectrometry (RBS) and nuclear reaction analysis (NRA). RBS can provide all the constituent concentrations in the films and the absolute determination of the number of atoms $/ \mathrm{cm}^{2}$. However RBS is not suited to detection of light atoms deposited on a substrate material of higher atomic mass. On the other hand, the NRA has the advantage that it allows to measure the areal concentrations of nitrogen and boron in $\mathrm{BNx}$ films on Si substrates, although calibration is required using standard specimens. These experiments were carried out on the 2 $\mathrm{MeV}$ Van de Graaff accelerator connected to an ultra high vacuum (UHV) chamber. For RBS measurement, a ${ }_{2}^{4} \mathrm{He}^{+}$ beam at $2.0 \mathrm{MeV}$, a total scattering angle of $168^{\circ}$ and a beam incident angle to the substrate normal or $60 \mathrm{deg}$. were used. $\mathrm{Zr}$ and $\mathrm{Pt}$ films, $1150 \AA$ to $3300 \AA$ in thickness, deposited on vitreous carbon plates were used as a substrate. NRA was performed using a deuteron beam of $1.7 \mathrm{MeV}$ and a beam incident angle of $20 \mathrm{deg}$. A peak from ${ }^{10} \mathrm{~B}(\mathrm{~d}, \alpha){ }^{8} \mathrm{Be}$ in an NRA spectrum of a standard sample appeared clearly without significant background, however a broad signal from ${ }^{11} \mathrm{~B}(\mathrm{~d}, \alpha){ }^{9} \mathrm{Be}$ appeared overlapping with a peak from

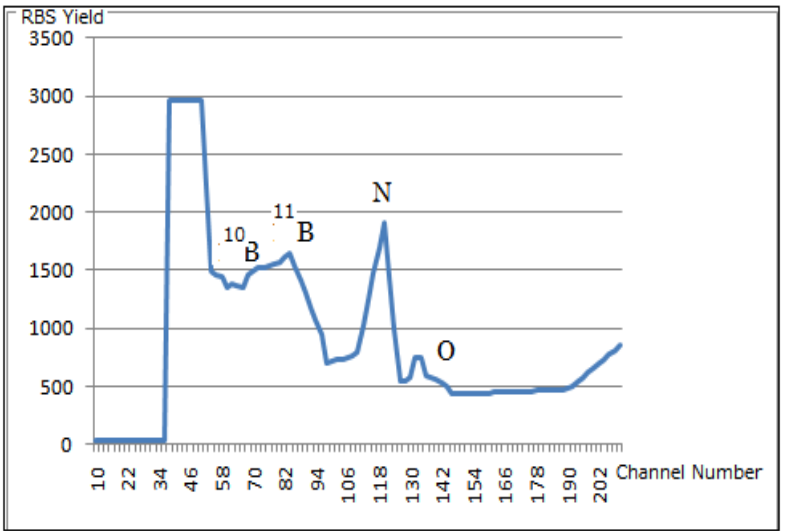

Fig.1

A RBS spectrum of a $\mathrm{BN}(1100$ $\AA) / Z r(3300 \AA) / C$ substrate, measured with a ${ }_{2} \mathrm{He}^{+}$ beam at $2.0 \mathrm{MeV}$, a total scattering angle of $168 \mathrm{deg}$ and a beam incident angle to substrate normal.

\author{
S. Takamiya \\ Tsuyama National College of Technology \\ lmhbatt999@yahoo.co.jp \\ T. Fukui \\ Tsuyama National College of Technology \\ s-505029@tsuyama-ct.ac.jp
}

${ }^{14} \mathrm{~N}(\mathrm{~d}, \alpha){ }^{12} \mathrm{C}$. Therefore the ${ }^{10} \mathrm{~B}(\mathrm{~d}, \alpha){ }^{8} \mathrm{Be}$ and ${ }^{14} \mathrm{~N}(\mathrm{~d}, \alpha){ }^{12} \mathrm{C}$ yields were estimated, since the ratio of ${ }^{11} \mathrm{~B}:{ }^{10} \mathrm{~B}$ measured by RBS was $0.83: 17$, which is well consistent with the natural isotopic ratio, ${ }^{11} \mathrm{~B}:{ }^{1} \mathrm{OB}=0.802: 0.192$. In the case of calculating the ${ }^{14} \mathrm{~N}(\mathrm{~d}, \alpha){ }^{12} \mathrm{C}$ yields, the signal from ${ }^{11} \mathrm{~B}(\mathrm{~d}$, $\alpha)^{9} \mathrm{Be}$ was deconvoluted by taking into account the shape of ${ }^{11} \mathrm{~B}(\mathrm{~d}, \alpha){ }^{9} \mathrm{Be}$ signal. The areal ratio ${ }^{14} \mathrm{~N} /{ }^{10} \mathrm{~B}$ was 7.73 and the error was -3.5 to $+3.2 \%$. These values will be used for determining composition of $\mathrm{BN}$ films. The conversion factor allows obtaining the composition of $\mathrm{BN}$ thin films on $\mathrm{Si}$ substrate.

\section{CONCLISIONS}

NRA and AES signals were calibrated to the RBS results for the $\mathrm{BN}$ films prepared carefully on the $\mathrm{Zr}$ coating vitreous carbon substrates, and following relations was obtained.

$$
\begin{aligned}
& \mathrm{N} / \mathrm{B}=0.13 \mathrm{~S}\left({ }^{14} \mathrm{~N}\right) / \mathrm{S}\left({ }^{10} \mathrm{~B}\right) \\
& \mathrm{N} / \mathrm{B}=0.58\left(\mathrm{I}_{\mathrm{N}} / \mathrm{I}_{\mathrm{B}}\right)
\end{aligned}
$$

These conversion factors allow to obtain the composition of thick BN films on $\mathrm{Si}$ substrate.

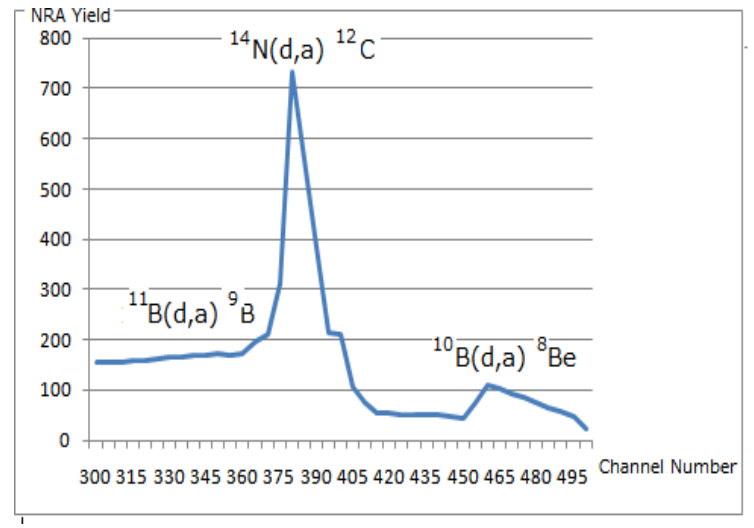

Fig,2 A NRA spectrum of a $\mathrm{BN}(1100$ $\AA) / \operatorname{Zr}(3300 \quad \AA) / C$ substrate, measured with a deuteron beam at $1.7 \mathrm{MeV}$ and a beam incident angle of $20 \mathrm{deg}$. 


\section{Nuclear reaction analysis for composition measurement of BN thin films}

\author{
T. Kobayashi \\ Tsuyama National College of Technology \\ Okayama, Japan 708-8509 \\ Phone : +81-868-24-8215, Fax : +81-868-8219 \\ t-koba@tsuyama-ct.ac.jp \\ T. Fukui \\ Tsuyama National College of Technology \\ Okayama, Japan 708-8509 \\ Phone : +81-868-24-8216, Fax : +81-868-8219 \\ wooran.46-45-.-v@ezweb.ne.jp
}

\author{
S. Takamiya \\ Tsuyama National College of Technology \\ Okayama, Japan 708-8509 \\ Phone : +81-868-24-8216, Fax : +81-868-8219 \\ lmhbatt999@yahoo.co.jp \\ H. Kanematsu \\ Suzuka National College of Technology \\ Mie, Japan 510-0294 \\ Phone : +81-59-368-1849, Fax :+81-59-368-1849 \\ kanemats@mse.suzuka-ct.ac.jp
}

Keywords: nuclear reaction, deuteron, Boron, Boron Nitride, Thin films, Rutherford backscattering spectrometry.

\section{ABSTRACT}

The composition of the BN film was determined using Rutherford backscattering spectrometry (RBS) and nuclear reaction analysis (NRA). RBS can provide all the constituent concentrations in the films and the absolute determination of the number of atoms $/ \mathrm{cm}^{2}$. However RBS is not suited to detection of light atoms deposited on a substrate material of higher atomic mass. On the other hand, the NRA has the advantage that it allows to measure the areal concentrations of nitrogen and boron in $\mathrm{BN}_{\mathrm{X}}$ films on $\mathrm{Si}$ substrates, although calibration is required using standard specimens. These experiments were carried out on the $2 \mathrm{MeV}$ Van de Graaff accelerator connected to an ultra high vacuum (UHV) chamber. For RBS measurement, a ${ }_{2}^{4} \mathrm{He}+$ beam at $2.0 \mathrm{MeV}$, a total scattering angle of $168^{\circ}$ and a beam incident angle to the substrate normal or $60 \mathrm{deg}$. were used. $\mathrm{Zr}$ and Pt films, $1150 \AA$ to $3300 \AA$ in thickness, deposited on vitreous carbon plates were used as a substrate. NRA was performed using a deuteron beam of $1.7 \mathrm{MeV}$ and a beam incident angle of 20 deg. A peak from ${ }^{10} \mathrm{~B}(\mathrm{~d}, \alpha){ }^{8} \mathrm{Be}$ in an NRA spectrum of a standard sample appeared clearly without significant background, however a broad signal from ${ }^{11} \mathrm{~B}(\mathrm{~d}, \alpha){ }^{9} \mathrm{Be}$ appeared overlapping with a peak from ${ }^{14} \mathrm{~N}(\mathrm{~d}, \alpha)^{12} \mathrm{C}$. Therefore the ${ }^{10} \mathrm{~B}(\mathrm{~d}, \alpha){ }^{8} \mathrm{Be}$ and ${ }^{14} \mathrm{~N}(\mathrm{~d}, \alpha){ }^{12} \mathrm{C}$ yields were estimated, since the ratio of ${ }^{11} \mathrm{~B}:{ }^{10} \mathrm{~B}$ measured by RBS was $0.83: 17$, which is well consistent with the natural isotopic ratio, ${ }^{11} \mathrm{~B}:{ }^{10} \mathrm{~B}=0.802: 0.192$. In the case of calculating the ${ }^{14} \mathrm{~N}(\mathrm{~d}, \alpha){ }^{12} \mathrm{C}$ yields, the signal from ${ }^{11} \mathrm{~B}(\mathrm{~d}, \alpha){ }^{9} \mathrm{Be}$ was deconvoluted by taking into account the shape of ${ }^{11} \mathrm{~B}(\mathrm{~d}$, $\alpha)^{9} \mathrm{Be}$ signal. The areal ratio ${ }^{14} \mathrm{~N} /{ }^{10} \mathrm{~B}$ was 7.73 and the error was -3.5 to $+3.2 \%$. These values will be used for determining composition of BN films. The conversion factor allows obtaining the composition of $\mathrm{BN}$ thin films on $\mathrm{Si}$ substrate.

\section{INTRODUCTION}

The composition of the $\mathrm{BN}$ film was determined using Rutherford backscattering spectrometry (RBS), nuclear reaction analysis (NRA) and Auger electron spectroscopy (AES). RBS can provide all the constituent concentrations in the films and the absolute determination of the number of atoms $/ \mathrm{cm} 2$. However RBS is not suited to detection of light atoms deposited on a substrate material of higher atomic mass, because the signals from both the film and the substrate overlap and this results in larger error in the signals from the film. To overcome this problem, an intermediate layer is sometimes used to push back the substrate signals. For example, usage of carbon substrate having $\mathrm{Si}$ or Fe layer as a intermediate layer [1][2], so that this intermediate layer pushes the signal from the carbon substrate back, resulting in high resolution of the $\mathrm{B}$ peak.

On the other hand, the NRA has the advantage that it allows to measure the areal concentrations of nitrogen and boron in BNx films on Si substrates, although calibration is required using standard specimens. Usage of different substrate materials is crucial for research on BN coatings, since it has been reported that $\mathrm{BN}$ phases depend on the materials of substrate [3][4]. In addition this technique minimises the uncertainty in the measurement of the relative variations of the N/B atomic ratio, because the signals from Copyright (C) 2011 by JSME 
nitrogen and boron are recorded in the same spectrum.

AES can be used for any substrate material and film thickness although it needs calibration using a standard sample the same as the NRA. AES is a surface analysis, therefore hydro-carbon, carbon-oxide and oxygen adsorbed on the surface of sample are detected, together with the elements of the sample. Thus, in most cases, the surface is bombarded with ions to remove the surface layer; however, in the case of much element material, the composition of the surface is altered due to difference of the sputtering yield among each element.

\section{EXPERIMANTAL CONDITION}

These experiments were carried out on the $2 \mathrm{MeV}$ Van de Graaff accelerator connected to a ultra high vacuum (UHV) chamber. For RBS measurement, a $42 \mathrm{He}+$ beam at 2.0 MeV, a total scattering angle of $168^{\circ}$ and a beam incident angle to the substrate normal or $60 \mathrm{deg}$. were used. $\mathrm{Zr}$ and Pt films, $1150 \AA$ to $3300 \AA$ in thickness, deposited on vitreous carbon plates were used as a substrate. NRA was performed using a deuteron beam of $1.7 \mathrm{MeV}$ and a beam incident angle of $20 \mathrm{deg}$. This energy value was chosen in order to obtain maximum cross section for the considered reactions and to ensure that the energy loss of the primary beam through a $500 \mathrm{~nm}$ thick layer does not induce a notable cross section variation [1][5][6]. AES was conducted using an AES analysis system, JAMP-7800 produced by JEOL, with the electron beam acceleration voltage of $10 \mathrm{keV}$, the beam diameter of $100 \mu \mathrm{m}$ and the beam incident angle $30 \mathrm{deg}$ to the substrate normal.

\section{RESULT}

\subsection{Calibration between RBS and NRA}

\subsubsection{Estimation of the conversion factor}

One example of RBS spectra measured for a sample( $\mathrm{BN}(1100 \AA) / \mathrm{Zr}(3300 \AA) / \mathrm{C}$ substrate) with a beam incident angle normal to the substrate is shown in Fig,1. The carbon substrate signal was shifted to a lower channel number, therefore, the peaks from $11 \mathrm{~B}$ and $10 \mathrm{~B}$ appeared clearly at channel numbers of 73 and 63, respectively,

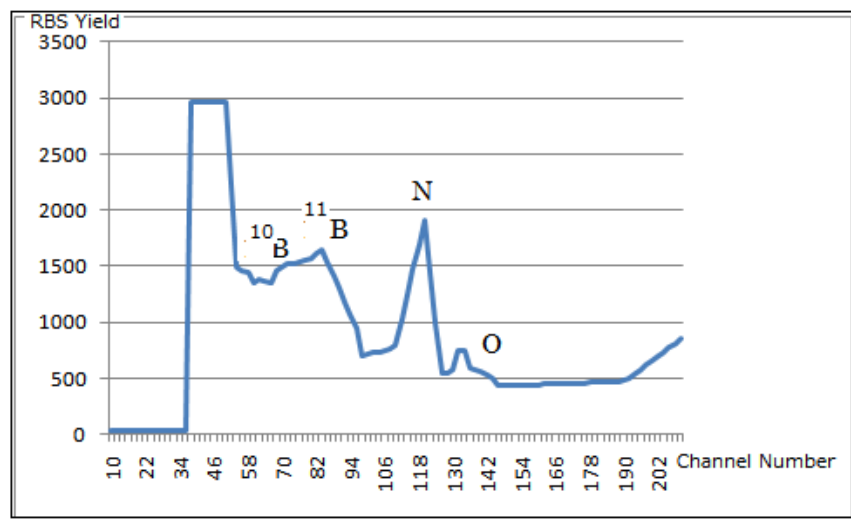

Fig.1 A RBS spectrum of a BN(1100 ̊)/ $\mathrm{Zr}(3300 \AA) / \mathrm{C}$ substrate, measured with a ${ }_{2}^{4} \mathrm{He}^{+}$beam at $2.0 \mathrm{MeV}$, a total scattering angle of $168 \mathrm{deg}$ and a beam incident angle to substrate normal. without an appreciable background signal. The calculated results of ${ }^{11} \mathrm{~B},{ }^{10} \mathrm{~B}$ and ${ }^{14} \mathrm{~N}$ yields and the ratio of elements are summarised in Table, 1 .

Table, $1{ }^{11} \mathrm{~B},{ }^{10} \mathrm{~B}$ and ${ }^{14} \mathrm{~N}$ yields and the $\mathrm{N} / \mathrm{B}$ atomic ratio obtained from the RBS spectrum of a $\mathrm{BN}(1100 \AA) / \operatorname{Zr}(3300$ A)/C substrate.

\begin{tabular}{|c|c|c|c|c|c|c|c|}
\hline \multirow[t]{2}{*}{ Condition } & \multirow{2}{*}{$\begin{array}{c}\text { Calculation } \\
\text { No. }\end{array}$} & \multirow[t]{2}{*}{ Element } & \multicolumn{2}{|l|}{ Channel } & \multirow{2}{*}{$\begin{array}{c}\text { Integrated } \\
\text { counts }\end{array}$} & \multirow{2}{*}{$\begin{array}{c}\text { Atomic } \\
\text { ratio }\end{array}$} & \multirow{2}{*}{$\begin{array}{l}\mathrm{N} / \mathrm{B} \text { atomic } \\
\text { ratio }\end{array}$} \\
\hline & & & rear & front & & & \\
\hline \multirow{7}{*}{$\begin{array}{c}\mathrm{He}^{+} \\
2 \mathrm{MeV} \\
168 \mathrm{deg} \\
20 \mu \mathrm{C}\end{array}$} & \multirow{3}{*}{1} & ${ }^{11} \mathrm{~B}$ & 73.5 & 93.5 & 6285 & 0.83 & \multirow{3}{*}{0.99} \\
\hline & & ${ }^{10} \mathrm{~B}$ & 63.8 & 73.7 & 1289 & 0.17 & \\
\hline & & $\mathrm{N}$ & 107.8 & 125.8 & 13310 & 0.99 & \\
\hline & \multirow[t]{2}{*}{2} & ${ }^{10} \mathrm{~B}+{ }^{11} \mathrm{~B}$ & 63.5 & 92.5 & 7363 & 1.00 & \multirow[t]{2}{*}{1.01} \\
\hline & & $\mathrm{N}$ & 107.4 & 126.4 & 13315 & 1.01 & \\
\hline & \multirow[t]{2}{*}{3} & ${ }^{10} \mathrm{~B}+{ }^{11} \mathrm{~B}$ & 63.5 & 92.5 & 7532 & 1.00 & \multirow[t]{2}{*}{0.99} \\
\hline & & $\mathrm{N}$ & 107.8 & 125.8 & 13310 & 0.99 & \\
\hline
\end{tabular}

The calculation was done three times. The N/B atomic ratio was 0.997 in average and the error was $+0.17 \sim-0.12 \%$. This error is within an error of $\pm 5 \%$ which results from the RBS process and the spectra deconvolution. The ratio of ${ }^{11} \mathrm{~B}$ : ${ }^{10} \mathrm{~B}$ was $0.83: 17$. This value is well consistent with the natural isotopic ratio, ${ }^{11} \mathrm{~B}:{ }^{10} \mathrm{~B}=0.802: 0.192$. Assuming that the density of the BN film is $2.2 \mathrm{~g} / \mathrm{cm}^{3}$, the thickness of this BN film is $1100 \AA$.

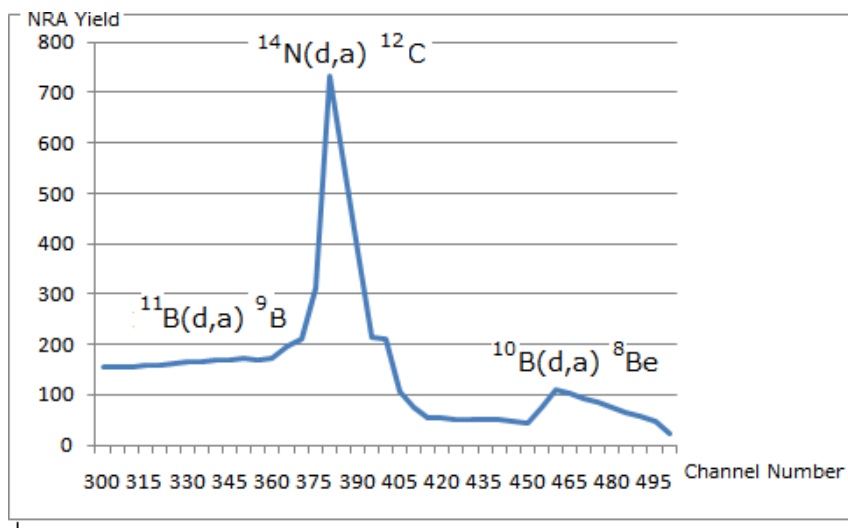

Fig,2 A NRA spectrum of a $\mathrm{BN}(1100 \AA) / \mathrm{Zr}(3300$ $\AA) / C$ substrate, measured with a deuteron beam at $1.7 \mathrm{MeV}$ and a beam incident angle of $20 \mathrm{deg}$.

An NRA spectrum of this sample is shown in Fig,2. A peak from ${ }^{10} \mathrm{~B}(\mathrm{~d}, \alpha){ }^{8} \mathrm{Be}$ appeared clearly at a channel of 472 without significant background; however a broad signal from ${ }^{11} \mathrm{~B}(\mathrm{~d}, \alpha){ }^{9} \mathrm{Be}$ appeared from $400 \mathrm{ch}$ to $330 \mathrm{ch}$, overlapping with a peak from ${ }^{14} \mathrm{~N}(\mathrm{~d}, \alpha){ }^{12} \mathrm{C}$. Therefore the ${ }^{10} \mathrm{~B}(\mathrm{~d}, \alpha){ }^{8} \mathrm{Be}$ and ${ }^{14} \mathrm{~N}(\mathrm{~d}, \alpha){ }^{12} \mathrm{C}$ yields were estimated. In the case of calculating the ${ }^{14} \mathrm{~N}(\mathrm{~d}, \alpha){ }^{12} \mathrm{C}$ yields, the signal from ${ }^{11} \mathrm{~B}(\mathrm{~d}, \alpha){ }^{9} \mathrm{Be}$ was deconvoluted by taking into account the shape of ${ }^{11} \mathrm{~B}(\mathrm{~d}$, $\alpha)^{9} \mathrm{Be}$ signal, which is shown in Fig,3.

Fig, 3 was obtained from a pure boron film deposited on a $\mathrm{Si}$ wafer by ion beam sputtering. The calculated results of ${ }^{10} \mathrm{~B}(\mathrm{~d}, \alpha){ }^{8} \mathrm{Be}$ and ${ }^{14} \mathrm{~N}(\mathrm{~d}, \alpha){ }^{12} \mathrm{C}$ yields are shown in Table, 2.

The areal ratio ${ }^{14} \mathrm{~N} /{ }^{10} \mathrm{~B}$ was 7.73 and the error was +3.2 -3.5\%. These values will be used for determining composition of $\mathrm{BN}$ films.

Consequently the conversion from the NRA areal ratio $\mathrm{S}\left({ }^{14} \mathrm{~N}\right) / \mathrm{S}\left({ }^{10} \mathrm{~B}\right)$ to the N/B atomic ratio, as shown in Fig, 4 , is formalised as $\mathrm{N} / \mathrm{B}=0.13 \mathrm{~S}\left({ }^{14} \mathrm{~N}\right) / \mathrm{S}\left({ }^{10} \mathrm{~B}\right)$. 


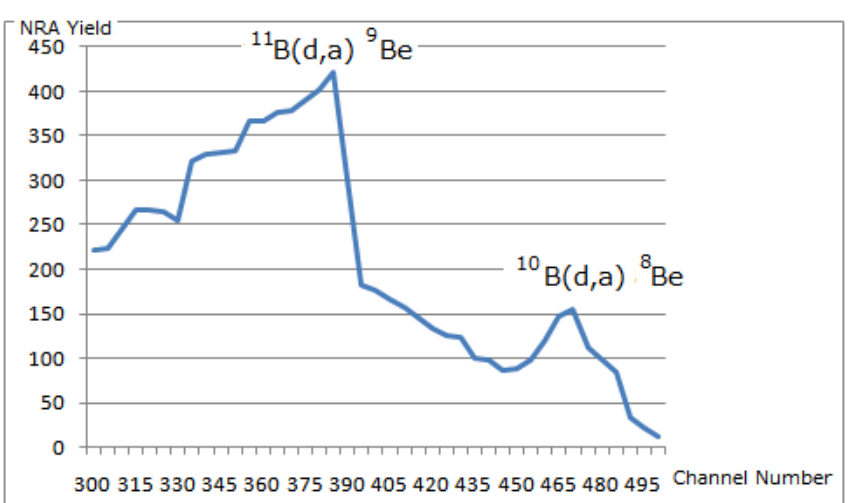

Fig,3 A NRA spectrum of a $B(1100 \AA) / Z r(2100 \AA) / C$ substrate, measured with a deuteron beam at $1.7 \mathrm{MeV}$ and a beam incident angle of $20 \mathrm{deg}$.

Table, $2{ }^{10} \mathrm{~B}$ and ${ }^{14} \mathrm{~N}$ yields and the areal ratio obtained from the NRA spectrum of a $\mathrm{BN}(1100 \AA) / \operatorname{Zr}(3300 \AA) / C$ substrate.

\begin{tabular}{|c|c|c|c|c|c|c|}
\hline \multirow[t]{2}{*}{ Condition } & \multirow{2}{*}{$\begin{array}{c}\text { Calculation } \\
\text { No. }\end{array}$} & \multirow[t]{2}{*}{ Element } & \multicolumn{2}{|l|}{ Channel } & \multirow{2}{*}{$\begin{array}{c}\text { Integrated } \\
\text { counts } \\
\end{array}$} & \multirow{2}{*}{$\begin{array}{l}\text { NRA areal ratic } \\
\mathrm{S}\left({ }^{14} \mathrm{~N}\right) / \mathrm{S}\left({ }^{10} \mathrm{~B}\right)\end{array}$} \\
\hline & & & rear & front & & \\
\hline \multirow{6}{*}{$\begin{array}{c}D^{+} \\
1.7 \mathrm{MeV} \\
20 \mathrm{deg} \\
90 \mu \mathrm{C}\end{array}$} & 1 & N & 369.9 & 404.6 & 8718 & 7.46 \\
\hline & & ${ }^{10} \mathrm{~B}$ & 456.1 & 492.1 & 1169 & \\
\hline & 2 & $\mathrm{~N}$ & 307.5 & 407.1 & 9142 & 7.98 \\
\hline & & ${ }^{10} \mathrm{~B}$ & 456.1 & 491.4 & 1151 & \\
\hline & 3 & $N$ & 369.2 & 406.5 & 9058 & 7.75 \\
\hline & & ${ }^{10} \mathrm{~B}$ & 456.1 & 492.1 & 1169 & \\
\hline
\end{tabular}

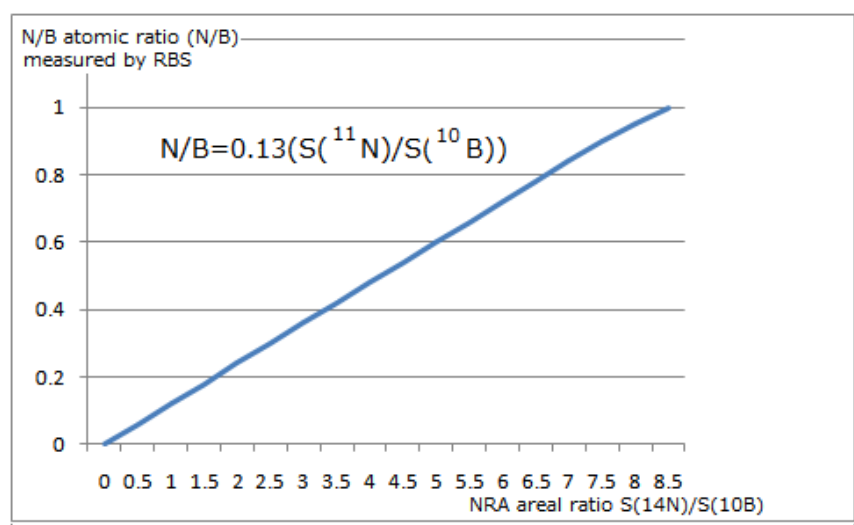

Fig,4 Conversion from NRA areal ratio to N/B atomic ratio. The BN film measured by RBS was analysed by NRA.

\subsubsection{Influence of the BN and Zr film thickness}

From the point of view of background subtraction, thin BN films are preferable, because RBS peaks at $2.0 \mathrm{MeV}$ from ${ }^{10} \mathrm{~B}$ and ${ }^{11} \mathrm{~B}$ of thicker BN films overlap as shown in Fig,1, although additional small error resulting from nitridification of the $\mathrm{Zr}$ intermediate layer may be given (the projected range of $250 \mathrm{eV} \mathrm{N}^{+}$in $\mathrm{Zr}$ layer is around $13 \AA$.). In order to separate the ${ }^{11} \mathrm{~B}$ peak from ${ }^{10} \mathrm{~B}$, thinner $\mathrm{BN}$ films having a thickness of around $300 \AA$ were prepared on carbon substrates coated with $\mathrm{Zr}$. These RBS spectra obtained at a beam incident angle of $60 \mathrm{deg}$. are shown in Fig,5(a) and (b). These two specimens have equal composition and thickness since they were prepared in the same batch, whereas they have different $\mathrm{Zr}$ layers in thickness, $1500 \AA$ for Fig,5(a) and $1150 \AA$ A for Fig,5(b).
The spectrum in Fig,5(a) shows that the peaks from ${ }^{11} \mathrm{~B}$ and ${ }^{10} \mathrm{~B}$ were separated. In Fig,5(b), peaks from ${ }^{11} \mathrm{~B}$ and ${ }^{10} \mathrm{~B}$ were also separated; however ${ }^{10} \mathrm{~B}$ peak overlapped with carbon signal, consequently only ${ }^{11} \mathrm{~B}$ yields can be measured. These calculated results are shown in Table,3.

The sample of Fig,5(a) has a N/B ratio of 1.0, an isotopic ratio ${ }^{11} \mathrm{~B}:{ }^{10} \mathrm{~B}=0.79: 0.21$. Assuming that the sample of Fig,5(b) has the isotopic ratio of boron equal to the sample of Fig,5(b), the N/B ratio is deduced to be 0.98 . These values are well accepted within reasonable error. As a conclusion, it is suggested that in the case of the BN film whose ${ }^{11} \mathrm{~B}$ and ${ }^{10} \mathrm{~B}$ peaks are separated in RBS spectra, measurement of ${ }^{11} \mathrm{~B}$ and ${ }^{14} \mathrm{~N}$ yields allow to estimate N/B ratio.

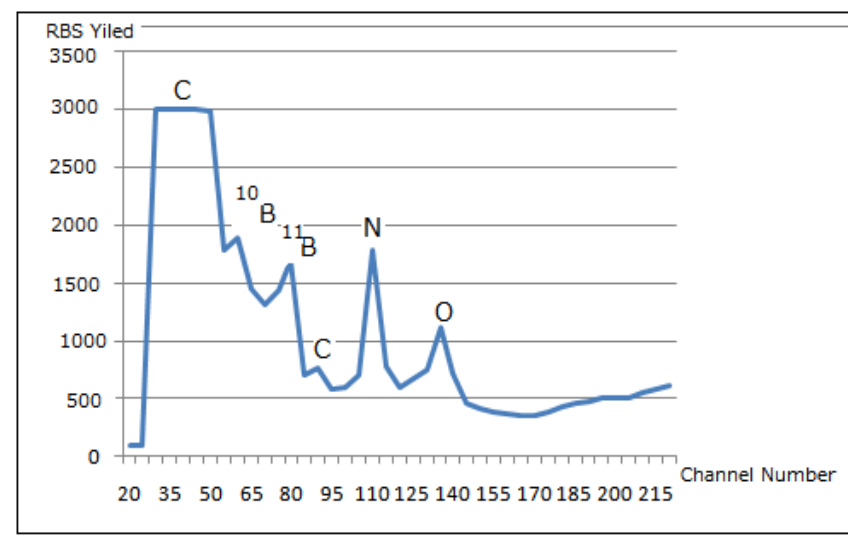

Fig,5(a)

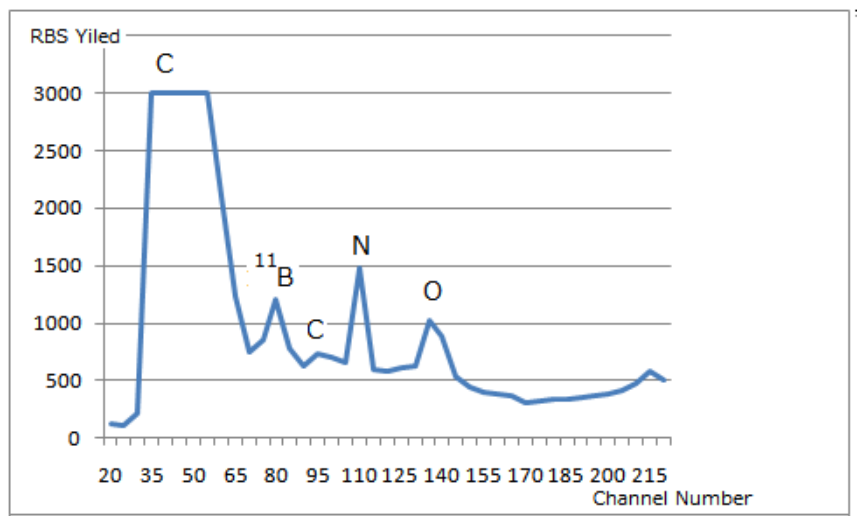

Fig,5(b) A RBS spectrum of (a) a BN(300 ̊̊)/Zr(1500 $\AA) / C$ substrate and (b) a $\mathrm{BN}(300 \AA) / \operatorname{Zr}(1150 \AA) / \mathrm{C}$ substrate, measured with $\mathrm{a}_{2}^{4} \mathrm{He}^{+}$beam at $2.0 \mathrm{MeV}$, a total scattering angle of $168 \mathrm{deg}$ and a beam incident angle of $60 \mathrm{deg}$.

Table, $3{ }^{11} \mathrm{~B},{ }^{10} \mathrm{~B}$ and ${ }^{14} \mathrm{~N}$ yields and the $\mathrm{N} / \mathrm{B}$ atomic ratios obtained from the RBS spectra of (a) a $\mathrm{BN}(300 \AA) / \operatorname{Zr}(1500$ $\AA) / C$ substrate and (b) a BN(300 $) / \operatorname{Zr}(1150 \AA) / C$ substrate.

\begin{tabular}{|c|c|c|r|r|r|r|r|}
\hline Condition & Specimen & Element & \multicolumn{2}{|c|}{ Channel } & Integrated & Atomic & $\begin{array}{l}\text { N/B atomic } \\
\text { ratio }\end{array}$ \\
\cline { 4 - 7 } & No. & & rear & \multicolumn{1}{|c|}{ front } & counts & rat10 & \\
\hline & & ${ }^{11} \mathrm{~B}$ & 73.7 & 83.6 & 2892 & 0.79 & \\
$\mathrm{He}^{+}$ & ZB1R60 & ${ }^{10} \mathrm{~B}$ & 61.9 & 68.7 & 794 & 0.21 & 1.01 \\
$2 \mathrm{MeV}$ & & $\mathrm{N}$ & 107.2 & 123.9 & 6355 & 1.01 & \\
\cline { 4 - 7 } $168 \mathrm{deg}$ & & ${ }^{11} \mathrm{~B}$ & 74.9 & 86.1 & 1978 & 0.79 & \\
$20 \mu \mathrm{C}$ & \multirow{2}{*}{ ZB1L60 } & ${ }^{10} \mathrm{~B}$ & - & - & - & $(0.21)$ & 0.98 \\
& & $\mathrm{~N}$ & 109.1 & 122.1 & 4203 & 0.98 & \\
\hline
\end{tabular}




\subsubsection{Discussion}

RUMP simulation was conducted in the case of Fig, 1 . The result is shown in Fig,6. The results which were discussed in Section 3.1.1 and 3.1.2 were clarified. In order to obtain composition of BN films having thickness greater than 1100 $\AA$, a $\mathrm{Zr}$ intermediate layer needs to have a thickness greater than $3300 \AA$ for RBS measurement with a $2.0 \mathrm{MeV}_{2}{ }^{4} \mathrm{He}^{+}$ beam and an incident beam angle to substrate normal. This condition gives a layer enough signal from carbon substrate to measure ${ }^{10} \mathrm{~B}$ peak without significant background signal. When a $\mathrm{Zr}$ layer is $2300 \AA$ in thickness, as shown by the experimental and the RUMP simulation results in Fig,7(a) and (b) respectively, only ${ }^{10} \mathrm{~B}$ peak appears clearly.

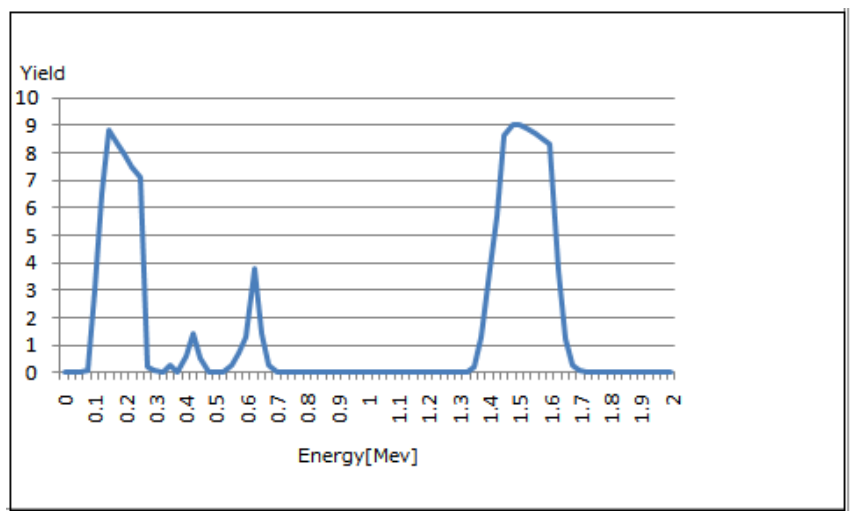

Fig,6 A simulated RBS spectrum by RUMP code for a sample of a $\mathrm{BN}(1100 \AA) / \mathrm{Zr}(3300 \AA) / \mathrm{C}$ substrate, measured with a ${ }_{2}^{4} \mathrm{He}^{+}$beam at $2.0 \mathrm{MeV}$, a total scattering angle of 168 deg and a beam incident angle to substrate normal.

However this specimen has a BN layer having $1100 \AA$ thickness therefore ${ }^{10} \mathrm{~B}$ and ${ }^{11} \mathrm{~B}$ peak can not be separated clearly, consequently accurate ${ }^{11} \mathrm{~B}$ yield are not given. For thinner BN films having thickness in $300 \AA$, a $\mathrm{Zr}$ intermediate layer with $1500 \AA$ in thickness, as shown the RUMP simulation results in Fig,8(a) and (b), is enough for RBS measurement with an incident beam angle of $60 \mathrm{deg}$.

Theoretically any heavy material can be adapted as the intermediate layer, but other factors need to be considered. A group of Burat and Bouchier [1][2] reported that they utilised $\mathrm{Fe}, \mathrm{Ag}$ or amorphous Si film with thickness of $1500 \AA$ as the intermediate layer for measuring the ${ }^{11} \mathrm{~B}$ and ${ }^{14} \mathrm{~N}$ peak, and suggested that in the case of $\mathrm{Fe}$ or $\mathrm{Ag}$ the resolution of the

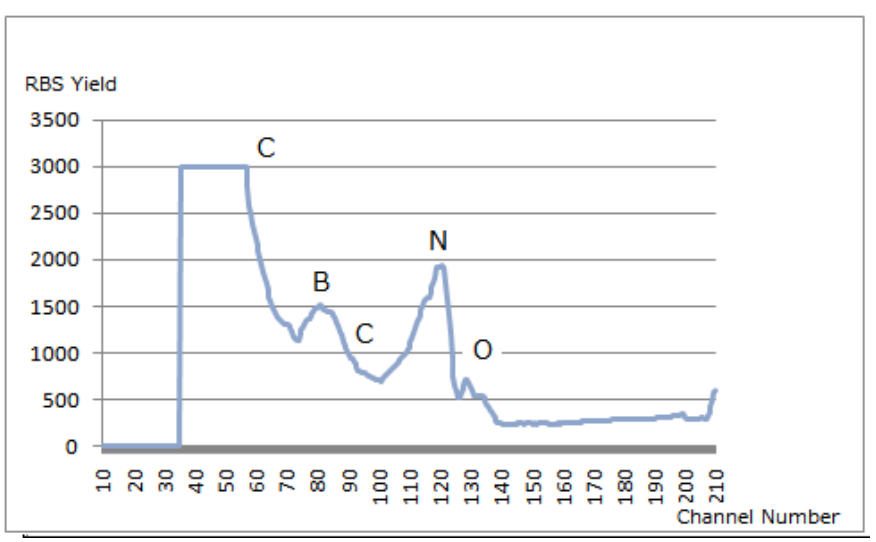

Fig,7(a)

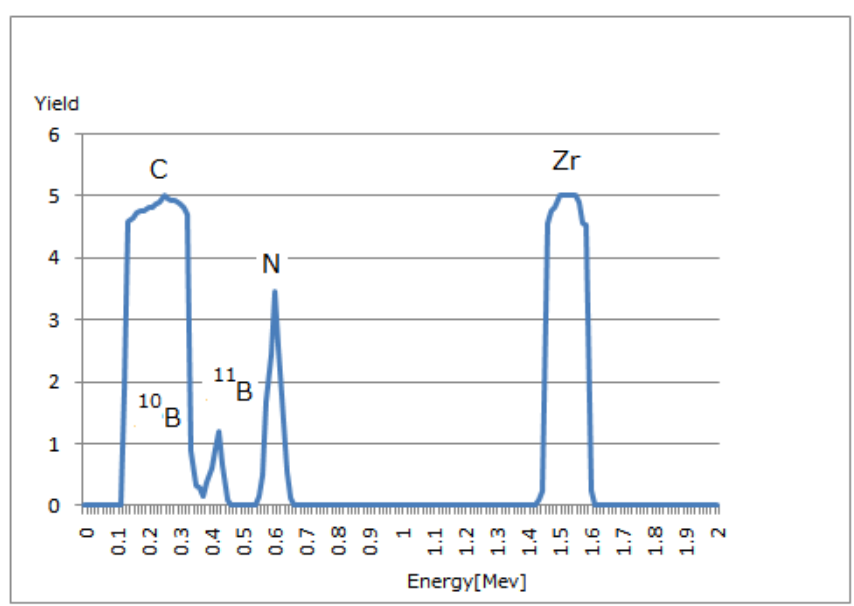

Fig,7(b) RBS spectra of a $\mathrm{BN}(1100 \AA) / \mathrm{Zr}(2300 \AA) / \mathrm{C}$ substrate, (a) measured and (b) simulated by RUMP code , with a ${ }_{2}^{4} \mathrm{He}^{+}$beam at $2.0 \mathrm{MeV}$, a total scattering angle of 168 deg and a beam incident angle to substrate normal.

boron peak was affected in some spectra by an unexpected partial superposition of the carbon plateau over the B peak which may leave error due to the roughness of the carbon substrate or to the polycrystalline structure of the intermediate layer, whereas this effect was not observed in the case of amorphous silicon. In this series of work, a Pt layer was also tried. As shown in Fig,9.

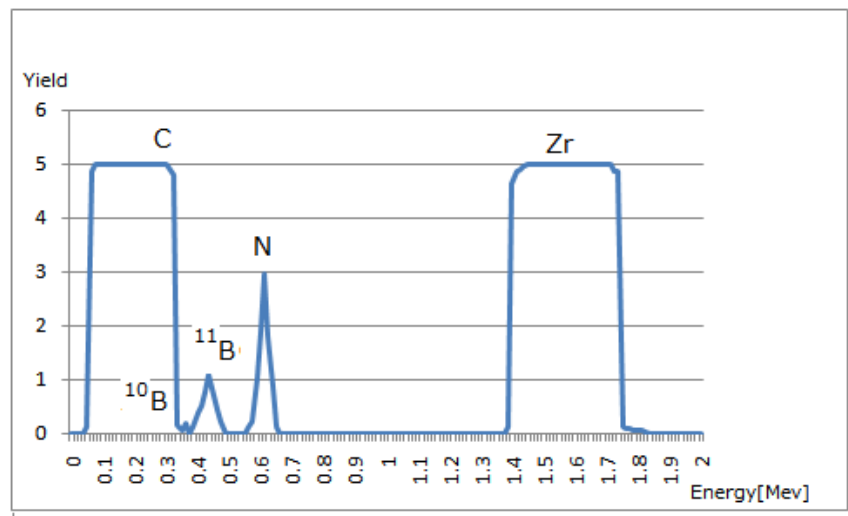

Fig,8(a)

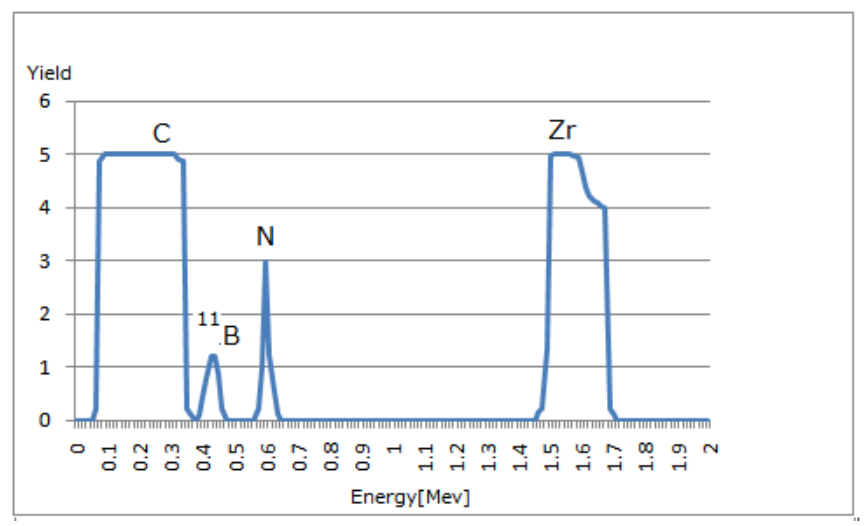

Fig,8(b) Simulated RBS spectra by RUMP code, (a) a $\mathrm{BN}(300 \AA) / \mathrm{Zr}(1500 \AA) / \mathrm{C}$ substrate and (b) a BN(300 $\AA) / \operatorname{Zr}(1150 \AA) / \mathrm{C}$ substrate, measured with a ${ }_{2}^{4} \mathrm{He}^{+}$beam at $2.0 \mathrm{MeV}$, a total scattering angle of $168 \mathrm{deg}$ and a beam incident angle of $60 \mathrm{deg}$. 


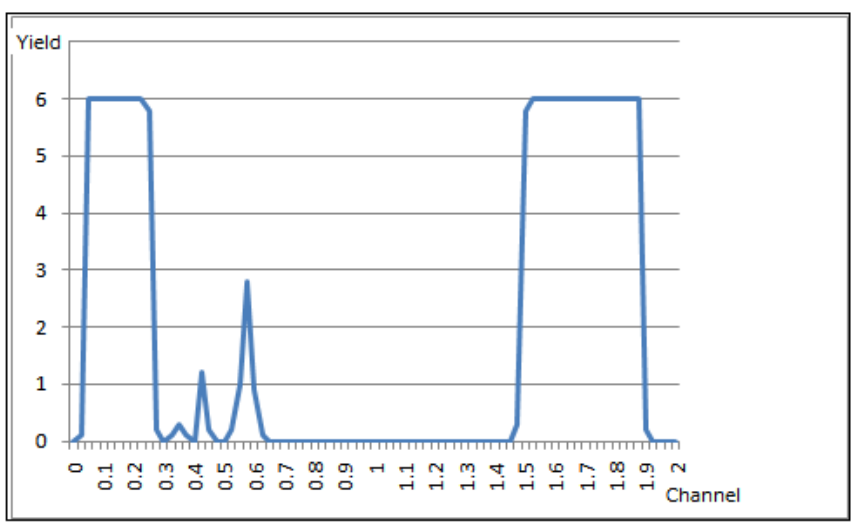

Fig,9(a)

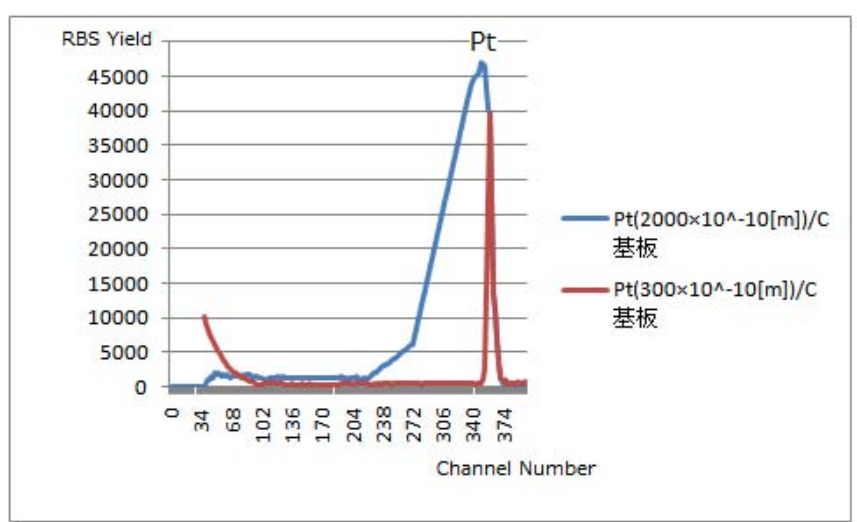

Fig,9(b) (a) A simulated RBS spectrum by RUMP code of a $\mathrm{BN}(500 \AA) / \operatorname{Pt}(2500 \AA) / \mathrm{C}$ substrate and (b) a measured RBS spectra of a $\mathrm{Pt}(2000 \AA) / \mathrm{C}$ substrate and a $\mathrm{Pt}(300 \AA) / \mathrm{C}$ substrate, with a ${ }_{2}^{4} \mathrm{He}^{+}$beam at $2.0 \mathrm{MeV}$, a total scattering angle of $168 \mathrm{deg}$ and a beam incident angle to substrate normal.

However, the RBS spectrum from a Pt layer with a thickness of $2500 \AA$, deposited by an ion beam sputtering with $1.0 \mathrm{keV} \mathrm{Ar}^{+}$and an ion incident angle to a Pt target of 80 deg., shows broad rear edge in Pt signal, although the dead time was kept less than $5 \%$. The reason has not been clarified, but it is suggested that energetic Pt atoms from target or reflected Ar ions might induce diffusion at the interface, or the deposited Pt film has a hill-and-ditch like morphology .

In addition, it should be noted that a trial NRA measurement of a bulk boron and a bulk pure hexagonal boron nitride (h-BN) was conducted in order to obtain standard spectra of a stoichiometric BN and pure boron. The results are shown in Fig, 10(a) and (b).

These spectra can provide peak heights of ${ }^{10} \mathrm{~B},{ }^{11} \mathrm{~B}$ and ${ }^{14} \mathrm{~N}$ by careful deconvolution. However, due to the difficulty of the deconvolution, the values could contain higher error than the values obtained from RBS measurement, which is carefully prepared as mentioned in Section 3.1.1 and 3.1.2.

The sample, which was deposited as $\mathrm{BN}$ film on $\mathrm{Si}$ substrate by dual ion beam sputtering method, and whose NRA spectrum is shown in Fig,11, has a NRA areal ratio $\mathrm{S}\left({ }^{14} \mathrm{~N}\right) / \mathrm{S}\left({ }^{10} \mathrm{~B}\right)$ of 6.16 .

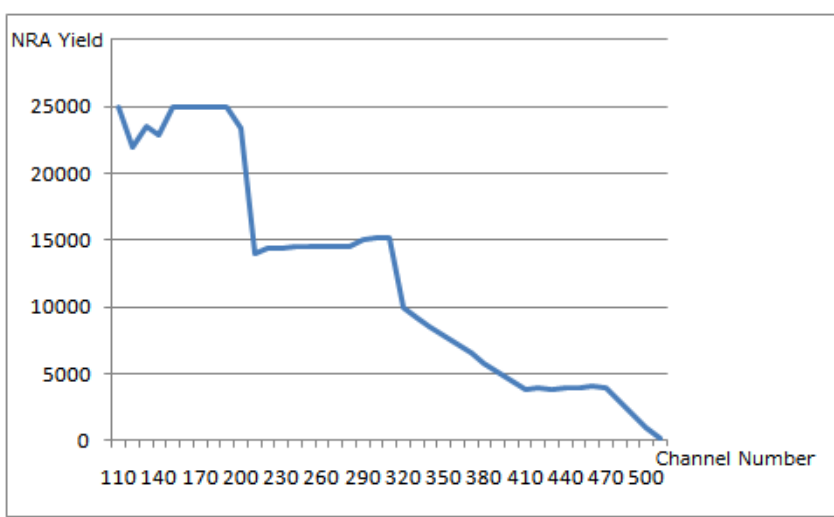

Fig, 10(a)

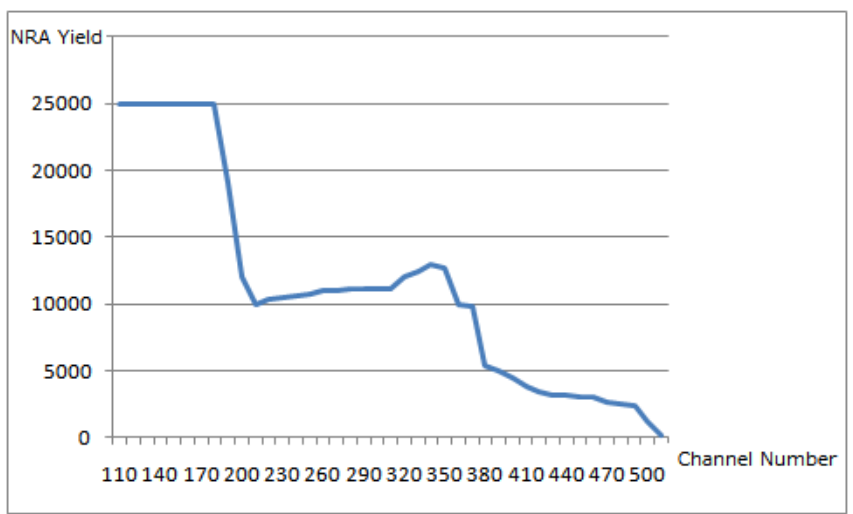

Fig,10(b) NRA spectra of (a) a bulk boron and (b) a bulk hexagonal boron nitride (h-BN) measured with a deuteron beam at $1.7 \mathrm{MeV}$ and a beam incident angle of 20 deg.

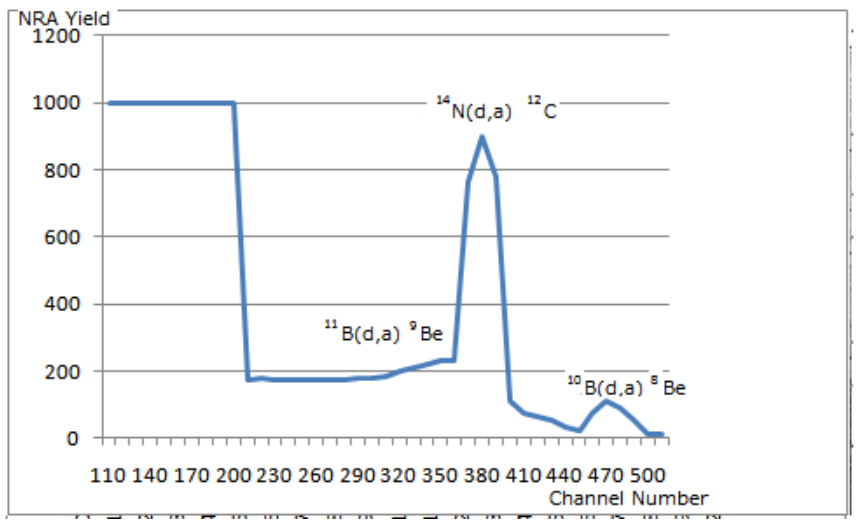

Fig,11 A NRA spectrum of a BN film on Si wafer, measured with a deuteron beam at $1.7 \mathrm{MeV}$ and a beam incident angle of $20 \mathrm{deg}$. The sample was deposited by dual ion beam sputtering method under a following condition: an ion energy of $500 \mathrm{eV}$, a substrate temperature of $300{ }^{\circ} \mathrm{C}$, an $\mathrm{Ar}+50 \% \mathrm{~N}_{2}$ gas fed into ion source, and an ion/B arrival ratio of 1.2 .

From Table, 1 and Table,2, the BN film having a N/B ratio of 0.997 (obtained from RBS) shows a NRA areal ratio $\mathrm{S}\left({ }^{14} \mathrm{~N}\right) / \mathrm{S}\left({ }^{10} \mathrm{~B}\right)=7.73$. Consequently, from Fig, 4 , the N/B atomic ratio of the BN film (shown in Fig,11) is estimated to be 0.796 . 


\subsection{Calibration between RBS and AES}

The samples having the N/B atomic ratios of 0.35 and 1.0 measured by RBS were analysed by AES, and the relation between the Auger electron intensity ratio(IN/IB) and the $\mathrm{N} / \mathrm{B}$ atomic ratio was investigated. In addition, an h-BN target for sputtering $(99.5 \% \mathrm{BN})$, sintered by a hot press process, was analysed by AES. The results are shown in Fig, 12 and Fig, 13.

The N/B atomic ratio of the h-BN target can be regarded as one, then the relation to the AES intensity ratio is plotted with the open square( $\square$ ).

In conclusion, it is found that the conversion from the AES electron intensity ratio (IN/IB) to the N/B atomic ratio is formalised as $\mathrm{N} / \mathrm{B}=0.58\left(\mathrm{I}_{\mathrm{N}} / \mathrm{I}_{\mathrm{B}}\right)$.

(a)
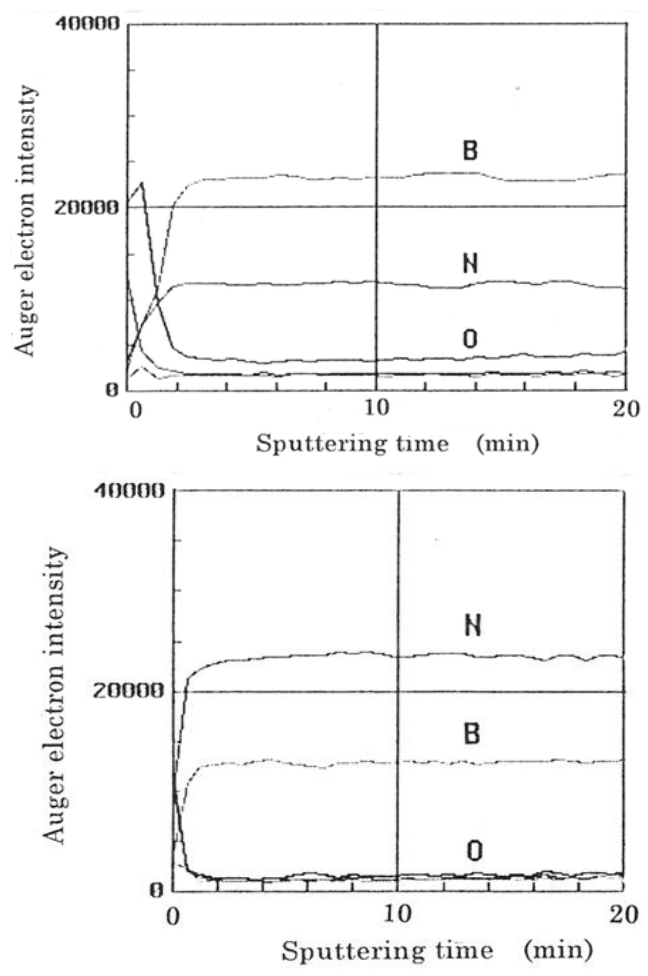

(c)

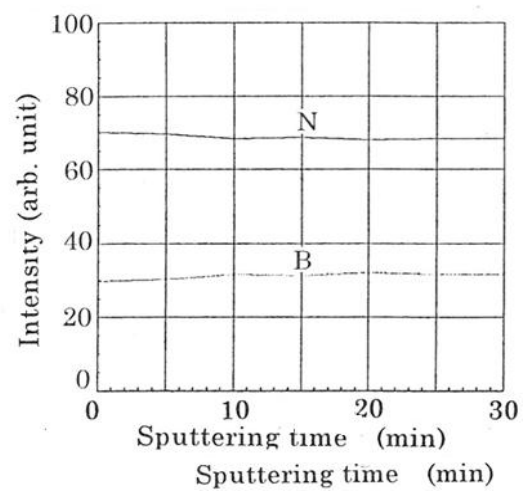

Fig,12 AES depth profiles of BN samples, (a) a BN film with a N/B atomic ratio $=0.35$, (b) a $\mathrm{BN}$ film with a N/B atomic ratio $=1.0$, and (c) a hot pressed h-BN target for sputtering with a N/B atomic ratio=1.0.

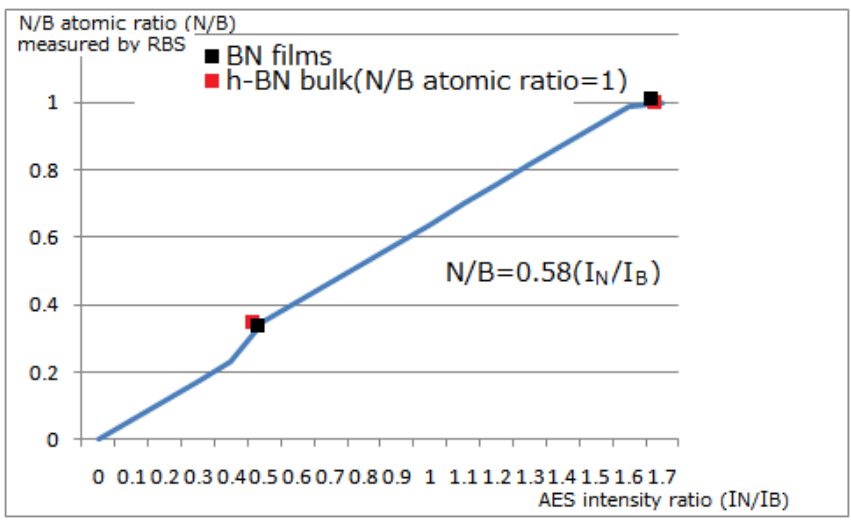

Fig,13 Conversion from AES intensity ratio to N/B atomic ratio. The BN films measured by RBS was analysed by AES.

\section{CONCLISION}

NRA and AES signals were calibrated to the RBS results for the $\mathrm{BN}$ films prepared carefully on the $\mathrm{Zr}$ coating vitreous carbon substrates, and following relations was obtained.

$\mathrm{N} / \mathrm{B}=0.13 \mathrm{~S}\left({ }^{14} \mathrm{~N}\right) / \mathrm{S}\left({ }^{10} \mathrm{~B}\right)$

$\mathrm{N} / \mathrm{B}=0.58\left(\mathrm{I}_{\mathrm{N}} / \mathrm{I}_{\mathrm{B}}\right)$

These conversion factors allow to obtain the composition of thick BN films on $\mathrm{Si}$ substrate.

\section{REFERENCES}

[1] O. Burat, D. Bouchier, V. Stambli, and G. Gautherin, J. Appl. Phys., 68 (1990) 2780.

[2] D. Bouchier and A. Bosseboeuf, Nucl. Instrum. Methods, B64 (1992) 765.

[3] D. J. Kester, K. S. Ailey, D. J. Lichtenwalner, and R. F. Davis, J. Vac. Sci. Technol., A12 (1994) 3074.

[4] M. Murakawa and S. Watanabe, Surf. Coatings Technol., 43/44 (1990) 128.

[5] S. T. Picraux, G. Amsel, and L. C. Feldman, "Tatania Warking Data",Tatania, Italy, Jun, 1974, P.61-N.

[6] H. J. Kim, W. T. Milner, and F. K. MacGowan, Nucl. Data A, 1 (1996) 203. 